\title{
II. Tuberculose oder Lupus der Nasenschleimhaut?
}

Von Maximilian Bresgen in Frankfurt am Main.

In No. $15 \mathrm{~d}$. W. beschreibt Max Schäffer sechs Fälle. in denen er eine eigenthümliche, besonders die knorpelige Nasenscheidewand zerstörende Geschwulsthildung fand. In zweien dieser Fälle wurden die entfernten Geschwülste von Nasse untersucht und Tuberkelbacillen in denselben gefunden. In keinem der Fälle vermochte Schäffer während der Beobachtungsdauer Lupusknötchen auf der äusseren Nase oder der Nasenschleimhaut festzustellen. Auch war Syphilis auszuschliessen. Schäffer sowohl wie $\mathrm{Nasse}$ halten deshalb die beschriebenen Geschwülste für Tuberkelgeschwülste, Es kann keinem Zweifel unterliegen, dass hier ein tuberculöser Process vorlag. Schäffer hat es aber auch für nöthig gehalten, das Nichtvorhandensein von Lupusknötchen in seinen Fällen ausdrücklich festzustellen. Lag aber nicht dennoch ein Lupus der Nasenschleimhaut vor? Es mag dies hier unentschieden bleiben. Aber ich will einen Fall mittheilen, in welchem der Verlauf innerhalb der Nase genau so sich gestaltete, wie Schäffer ihn in seimen Fällen beschrieben hat, und in welchem die Geschwulstmassen genau dasselbe Aussehen, wie in diesen Fällen, darboten. Ich konnte aber auch beobachten, wie sich in der Haut der äusseren Nase Lupusknötchen an verschiedenen Stellen nach und nach entwickelten, nachdem dieselbe vorher ganz frei gewesen war. Diese Lupusknötchen wurden von Herrn Collegen Herxheimer hierselbst als solche erkannt und auch mit Erfolg bisher behandelt. Ein ganz ähnlicher Fall kam noch kürzlich zu meiner Beobachtung, entzog sich aber schon nach wenigen Tagen der weiteren Behandlung. Ausserdem erinnere ich mich aus früheren Jahren noch zweier Fälle, in welchen jedoch kein Lupus der äusseren Nase während meiner Beobachtungszeit bestand; dieselben waren mir damals sehr unklar und wurden deshalb von mir, ohne allerdings sicheren Anhalt dafür zu haben, als der Syphilis verdächtig angesehen.

Der nunmehr zu beschreibende Fall betrifft eine jetzt 38 jährige Dame (C. 962. I. 171), die ich bereits vor 7 Jahren an chronischer Rhinitis behandelte, die dann aber von mir fast 6 Jahre lang nicht gesehen wurde. Im November $1885 \mathrm{kam}$ sie wieder zu mir mit der Klage, dass seit etwa einem halben Jahre ihre linke Nasenhälfte weniger frei, als früher, sei, dass vorne an der Scheidewand eine rothe Geschwulst sässe, die sehr leicht blute. Ich fand die äussere Nase vollkommen normal und ohne jedwede Andeutung von Knötchenbildung. An der Scheidewand links vorne fand ich eine rothe, höckerige, haselnussgrosse, granulirende Geschwulstmasse, durch welche ich mit einer Sonde in die rechte Nasenhöhle gelangte; an der Scheidewand rechts waren weniger Granulationen, als links, zu sehen; die Oeffnung war damals etwa erbsengross. Im übrigen war die Nasenschleimhaut bis auf eine mässige chronische Rhinitis vollkommen normal. Ich dachte nun zunächst an Syphilis, obschon kein Anhalt dafür zu finden war. Jodkalium hatte auch gar keinen Einfluss. Dagegen gelang es mir durch Galvanokaustik und Chromsäure die Granulationen zu zerstören. Auffallend war mir dabei jedoch, dass die Oeffnung in der Scheidewand immer grösser wurde und da und dort stets neue Granulationen aufschossen. Ich kam dadurch auf den Gedanken, es könne Lupus vorliegen, zumal mir die Kranke eines Tages mittheilte, ihr Schwager liege an Lungen- 
schwindsucht schwerkrank darnieder. Auf weiteres Befragen erfulır ich sodann auch, dass sie vielfach in uähere Berührung mit demselben gekommen sei und dass sie an der Nasenscheidewand links öfters kleine Krusten habe entfernen müssen, wodurch die Nase vorne manchmal wund gewesen sei. Eine schon frïher vorgenommene Untersuchung der Lungen der Kranken hatte negatives Resultat ergeben. Die fernere Belaandlung bestand nun neben fortgesetzten allgemeinen Massuahmen in möglichster Zerstörung der stets wieder: neu und fortkriechend an anderen Stellen aufschiessenden Granulationeu. Im Mai 1886 zeigten sich einmal zwei rothe erhabene Fleckchen an der äusseren Nase links nahe der Spitze, doch gingen dieselben wieder soweit zurück, dass man sie kaum noch erkennen komnte. Sie stellten sich aber bald wieder ein und zeigten sich jetzt als deutliche Knötchen, deren nunmehr auch 5-6 in einem Haufen standen. Im Juni wurde diese Affection von Dr. Herxheimer als Lupus erkannt und in Behandlung genommen. Trotz fortgesetzter galvanokaustischer Zerstörung der Granulationen in der Nase wucherten diese doch immer wieder und breiteten sich sogar aus, und zwar links nach oben gegen das Nasendach und die Spitze hin sowie auf der rechten Seite besonders nach dem Nasenboden hin, ohne jedoch auf diesen selbst überzugreifen; am harten Gaumen hat sich bis heute noch keine Betheiligung gezeigt. Später verbreiteten sich in beiden Nasenhälften die Granulationen auf die Nasenflïgel und das vordere Ende der unteren Muschel. Ueberall ging ich denselben mit dem Galvanokauter, theilweise auch mit reiner Chromsäure nach. Schliesslich benutzte ich nur noch den Galvanokauter, vor dessen Anwendung stets cocainisirt wurde, in sehr ausgedehnter Weise und bis in die gesund erscheinende Umgebung hinein. Damit erst gelang es mir, wie es jetzt seit einigen Wochen scheint, des zerstörenden Processes Herr zu werden. Auch die äussere Nase ist augenblicklich, wie schon mehrere Male, ganz frei von Knötchenbildung. Zn bemerken ist, dass im Januar 1887 plötzlich auf der Mitte des rechten Nasenflügels aussen drei kleine Knötchen sichtbar wurden. Als ich genauer in der Nase zusah, fand ich an ziemlich entsprechender Stelle, oben etwas nach hinten und gegen das vordere Ende der unteren Muschel hin mehrere schwammige Granulationen, die erst nach mehrmaliger Anwendung der Galvanokaustik beseitigt werden konnten. Die äusseren Knötchen wurden auch in Behandlung genommen und verschwanden dann bald. Ganz ähnlich hatten sich früher während der Behandlung der ursprünglichen Knötchen an der Spitze (links) der Nase auf dem linken Nasenflügel Knötchen gezeigt, nachdem bereits innen an der Schleimhaut die schwammigen Granulationen von mir galvanokaustisch behandelt wurden. - Die anfänglich entfernte grössere Gramulationsmasse wurde leider nicht aufgehoben, so dass eine genauere Untersuchung nicht mehr vorgenommen werden konnte.

Bemerkenswerth in dem Falle ist der Verlauf, durch welchen festgestellt wurde, dass erst nach 13 monatlichem Bestehen der Schleimhauterkrankung Knötchenbildung in der Nasenhaut sich einstellte, und dass ferner mit dem Fortschreiten des Schleimhantprocesses an den nahegelegenen Stellen der Nasenhaut weiter Knötchen sich bildeten. Bemerkenswerth ist auch, dass der Erfolg der äusseren Behandlung von dem Erfolge der Schleimhautbehandlung wesentlich abhängig erschien. Erst nachdem ich zu ausgiebiger Zerstörung der Granulationen bis in die gesund erscheinende Schleimhaut hinein mich entschloss, besserte sich auch rascher und anhaltender der lupöse Process der Nasenhaut.

Wenn der lupöse Process histologisch als ein tuberculöser aufgefasst werden soll, so liegt es in vorliegenden Falle sehr nahe, das Vorhandengewesensein einer fïr das Wachsthum des Tuberkelbacillus geeigneten Schleimhaut anzunehmen: Vor Jahren hatte ich die Kranke bereits an chronischer Rhinitis behandelt; vor dem Auftreten der Geschwulst in der linken Nase hatte die Kranke ofters Gelegenheit, Krusten von der später erkrankten Stelle zu entfernen; zweifellos wurde diese dadurch verwundet. In diese Zeit fiel auch der nähere Umgang mit ihrem an hochgradiger Lungentuberculose darniederliegenden Schwager. Es läge also sehr nahe, hier eine direkte Infection anzunehmen. Diese letztere kann aber auch stattgefunden haben, ohne dass sie von Einfluss auf die Entstehung des lupösen Processes gewesen ist. So kann auch in den Schäffer'schen Fällen der Lupus der Nasenschleimhaut - und als solchen möchte ich die geschilderte Erkrankung doch ansehen tuberculös geworden sein. Wirkliche Tuberculose der Nasenschleimhaut macht doch keine Granulationsgeschwülste; wohl aber können Geschwïlste tuberculös werden, wie Schäffer ja selbst einen solchen Fall als Tuberkelgeschwulst des Kehlkopfes gleichzeitig beschrieben hat.

Dass die knorpelige Nasenscheidewand mit Vorliebe befallen zu werden scheint, mag daran liegen, dass das Bohren mit dem Fingernagel in der Nase, um Krusten zu entfernen, gerade erstere vornehmlich verletzt, wie ja schon lange (Störk) bekannt ist, dass Perforationen des Septums ohne andere zerstörende Processe als lediglich durch Bohren mit dem Fingernagel entstehen können; ich selbst habe solche Fälle gesehen.

Wäre in unserem Falle der Schleimhautprocess nicht auf die Nasenhaut durch Weiterkriechen übergegangen und hätte dort nicht Knötchenbildung von unzweifelhaft lupöser Natur hervorgerufen, so wären, da eine mikroskopische Untersuchung nicht mehr stattfinden konnte, immer noch Zweifel an der Richtigkeit der Diagnose möglich gewesen, wenn anch das klinische Bild die letztere sicherlich rechtfertigte. Ob Tuberkelbacillen im lupösen Gewebe gefunden werden oder nicht, erscheint für die Diagnose vorläufig noch nicht massgebend; zweifelhaft aber erscheint es uns, ob man jede Geschwulst, in der an einzelnen Stellen einzelne Tuberkelbacillen nachgewiesen werden, deshalb als Tuberkelgeschwīlste bezeichnen muss, oder ob man nicht vielmehr, wie ich vorhin bereits darlegte, von einer tuberculös gew ord enen Geschwulst sprechen soll.

Schliesslich möchte ich darauf hinweisen, dass mein Fall in unzweifelhafter Weise die Neiss er'sche Ansicht - nan vergleiche meine Bemerkung darïber in Boerner's Jahrbuch der praktischen Medicin. Jahrgang 1885. Seite 537. Stuttgart, Enke -, dass ein Gesichtslupus in der Regel als von einem Schleimhautlupus ausgegangen zu betrachten sei. 